\title{
Authors and Co-Authors
}

This book has a number of authors and co-authors who have contributed to the overall product in different ways and roles.

Three main authors have composed and principally written the book:

Stefan Baumgärtner - Background in physics (MSc) and economics $(\mathrm{PhD})$, Assistant Professor of Ecological Economics, Alfred-Weber-Institute of Economics, University of Heidelberg, Germany (baumgaertner @uni-hd.de).

Malte Faber - Background in mathematics and economics (MA, PhD), Professor Emeritus of Economics, Alfred-Weber-Institute of Economics, University of Heidelberg, Germany (faber@uni-hd.de).

Johannes Schiller - Background in physics (MSc) and economics (PhD), Senior Researcher, Department of Economics, UFZ Centre for Environmental Research, Leipzig-Halle, Germany (johannes.schiller@ufz.de).

Cooperating authors have made significant contributions that have essentially shaped the overall argument and the character of the book. Their role is acknowledged in the respective chapters of the book:

Thomas Petersen - Background in philosophy (MA, PhD), Assistant Professor of Philosophy, Institute of Philosophy, University of Heidelberg, Germany (thomas.petersen@urz.uni-heidelberg.de).

John Proops - Background in mathematics and physics (BA), engineering physics (MSc) and economics (PhD), Professor of Ecological Economics, School of Politics, International Relations and the Environment, Keele University, Keele, UK (j.l.r.proops@keele.ac.uk).

Ralph Winkler - Background in physics (MSc) and economics (MA, $\mathrm{PhD}$ ), Marie-Curie Fellow, School of Politics, International Relations and the Environment, Keele University, Keele, UK (r.t.winkler@pol.keele. ac.uk). 
Contributing authors have made important contributions to individual chapters of the book. Their role is acknowledged in the respective chapters:

Jakob de Swaan Arons - Background in chemical engineering (MSc, $\mathrm{PhD}$ ), Professor Emeritus of Chemical Engineering, Delft University of Technology, Delft, The Netherlands, and Chair of Industrial Ecology, Tsinghua University, Beijing, China (jakobdeswaanarons@yahoo.com).

Harald Dyckhoff - Background in mathematics, physics, business administration (MA) and economics (PhD), Professor of Industrial Economics and Environmental Economics, Institute of Business Administration, Technical University of Aachen, Germany (dyckhoff@lut.rwthaachen.de).

Frank Jöst - Background in economics (MA, PhD), Assistant Professor of Economics, Alfred-Weber-Institute of Economics, University of Heidelberg, Germany (frank.joest@uni-hd.de).

Eva Kiesele - Background in physics and economics (MSc), Research Assistant, Alfred-Weber-Institute of Economics, University of Heidelberg, Germany (kiesele@eco.uni-heidelberg.de).

Georg Müller-Fürstenberger - Background in chemistry (BSc) and economics (MA, PhD), Assistant Professor of Economics, Institute of Applied Microeconomics, University of Berne, Switzerland (georg.mueller @vwi.unibe.ch). 